\title{
Asthma, Chronic Obstructive Pulmonary Disease (COPD), and the Overlap Syndrome
}

\author{
Mohammad Obadah Nakawah, MD, Clare Hawkins, MD, and Farouk Barbandi, MD
}

Asthma and chronic obstructive pulmonary disease (COPD) are highly prevalent chronic diseases in the general population. Both are characterized by heterogeneous chronic airway inflammation and airway obstruction. In both conditions, chronic inflammation affects the whole respiratory tract, from central to peripheral airways, with different inflammatory cells recruited, different mediators produced, and thus differing responses to therapy. Airway obstruction is typically intermittent and reversible in asthma but is progressive and largely irreversible in COPD. However, there is a considerable pathologic and functional overlap between these 2 heterogeneous disorders, particularly among the elderly, who may have components of both diseases (asthma-COPD overlap syndrome). The definitions for asthma and COPD recommended by current guidelines are useful but limited because they do not illustrate the full spectrum of obstructive airway diseases that is encountered in clinical practice. Defining asthma and COPD as separate entities neglects a considerable proportion of patients with overlapping features and is largely based on expert opinion rather than on the best current evidence. The presence of different phenotypes or components of obstructive airway diseases, therefore, needs to be addressed to individualize and optimize treatment to achieve the best effect with the fewest side effects for the patient. Although specific interventions vary by disease, the treatment goals of obstructive airway diseases are similar and driven primarily by the need to control symptoms, optimize health status, and prevent exacerbations. (J Am Board Fam Med 2013;26: 470-477.)

Keywords: Asthma, Chronic Obstructive Airway Diseases, COPD, Overlap Syndrome

\section{Pathophysiology of Asthma and Chronic Obstructive Pulmonary Disease (COPD)}

The 3 common pathophysiological components of obstructive airway diseases, including asthma and COPD, are airway inflammation, airway obstruction (AO), and airway hyperresponsiveness (AHR). While chronic inflammation is the central component of all obstructive lung diseases, $\mathrm{AO}$ is the end result and can have both dynamic (bronchospastic) and static (structural) components (Figure 1).

This article was externally peer reviewed.

Submitted 13 September 2012; revised 26 February 2013; accepted 27 February 2013.

From Department of Family Medicine, San Jacinto Methodist Hospital, Baytown, TX.

Funding: none.

Conflict of interest: none declared.

Corresponding author: Mohammad Obadah Nakawah, MD, San Jacinto Methodist Hospital, 4301 Garth Road, Suite 300, Baytown, Texas 77521 (E-mail: Jdomon@tmhs.org).

\section{Chronic Airway Inflammation}

The underlying chronic inflammation traditionally has been considered primarily eosinophilic and driven by CD4 cells in asthma but neutrophilic and driven by CD8 cells in COPD. ${ }^{1,2}$ The patterns of inflammation associated with these conditions, however, are heterogeneous, with a significant overlap. Both noneosinophilic and neutrophilic asthma have been described, and these are hypothesized to confer resistance to steroids. ${ }^{3,4}$ Asthmatics who smoke or exhibit severe disease with fixed obstruction have an increased number of neutrophils in their airways, similar to COPD. In both asthma and COPD, smoking promotes neutrophilic inflammation, which results in increased steroid resistance. ${ }^{5,6}$ On the other hand, eosinophilic inflammation has been observed in the airways of some patients with COPD and is associated with greater reversibility of airflow obstruction when treated with corticosteroids. ${ }^{7}$ 
Figure 1. The pathophysiological components of obstructive airway diseases including asthma, chronic obstructive pulmonary disease, and their overlap. Chronic airway inflammation is the central component of all obstructive lung diseases, whereas airway obstruction (AO) and airway hyperreactivity (AHR) are important features. AHR can result in bronchospasm ("dynamic" A0), whereas airway edema, mucus plugs, and airway remodeling can cause a "static" or "stuctural" A0.

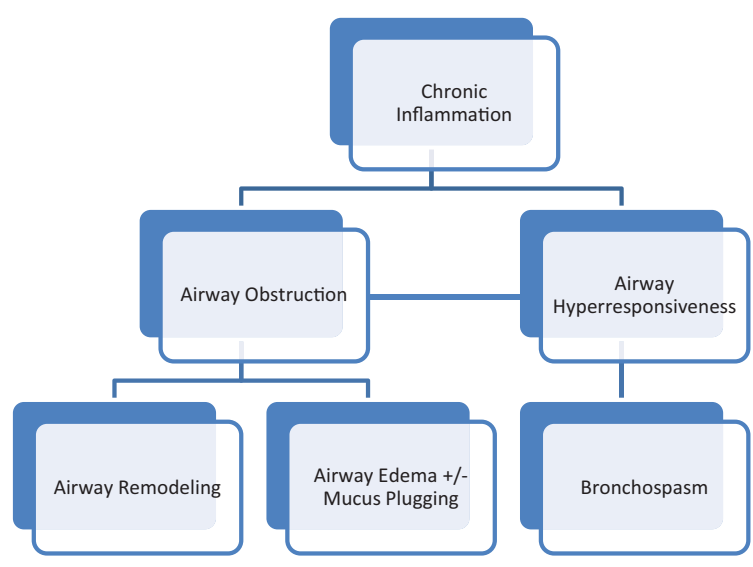

Superimposed on these chronic inflammatory states are acute inflammatory episodes, which correspond to exacerbations of asthma and COPD. Exacerbations are episodes of worsening symptoms of variable severity; they are usually triggered by respiratory infections and associated with increased inflammatory burden in the lower airways. Available data suggest that frequent severe exacerbations are associated with increased morbidity and mortality, poor health status, and a faster decline in lung function in both asthma and COPD, so prevention and optimal treatment of exacerbations is a global priority. 8,9

Histopathological studies of patients with asthma and COPD have established that these obstructive airway diseases involve not only the proximal large airways ( $>2 \mathrm{~mm}$ in diameter), but also the distal small airways $(<2 \mathrm{~mm}$ in diameter). Although asthma was originally described as an inflammatory disease that predominantly involves the central airways, pathologic and physiologic evidence suggests that airway inflammation and remodeling extends beyond the central airways to the peripheral airways and even the lung parenchyma. Peripheral airways, including lung tissue, have been recognized as a predominant site of airflow obstruction in asthmatics. ${ }^{10}$ Similarly, airway inflammation oc- curs in all parts of the respiratory tract in patients with COPD. The latter predominantly affects the small airways and lung parenchyma, although large airways remain the major source of the hypersecretion associated with the production of sputum. ${ }^{11}$

\section{Airway Obstruction}

AO results from bronchospasm, mucosal edema and inflammation, mucus hypersecretion and the formation of mucus plugs, as well as structural changes including hypertrophy and hyperplasia of the airway smooth muscle. Some components of these structural airway changes (collectively referred to as airway remodeling) are irreversible and associated with a progressive loss of lung function that is not prevented or fully reversible by current therapy. ${ }^{1,12}$

As mentioned earlier, the pathophysiology in asthma and COPD involves both central and peripheral airways, with the small airways being the major site of airflow limitation in both diseases. Furthermore, airway remodeling occurs throughout the respiratory tract; remodeling of the small airways is largely responsible for the decline in lung function in COPD and long-standing asthma. ${ }^{12}$ These findings are of great clinical significance and highlight the need to consider the peripheral airways as a target in any therapeutic strategy for treatment of asthma, COPD, or the overlap syndrome.

\section{Airway Hyperresponsiveness}

AHR, an exaggerated bronchoconstrictor response to a wide variety of stimuli, and bronchodilator reversibility are characteristic of many inflammatory airway diseases. In general, the responses to a bronchoconstrictor and bronchodilator have been considered to reflect the same underlying pathophysiological abnormality, and it has been assumed that the 2 measures are highly correlated. Thus, provocation challenges often have been replaced with reversibility tests, especially in severe $\mathrm{AO}$, for which provocation tests are contraindicated. ${ }^{13}$ Asthma and COPD resemble each other in that they both may show variable severity of AHR and hence bronchodilator reversibility. ${ }^{14,15}$ AHR is present in almost all patients with asthma, at least when they are experiencing symptoms, and in up to two thirds of patients with COPD, especially when reassessed overtime. ${ }^{14}$ 
AHR, which increases in prevalence with age and smoking, is present in approximately $10 \%$ to $20 \%$ of the general population and is frequently asymptomatic. Asymptomatic AHR is a risk factor for the development of asthma and COPD and is associated with new symptoms of wheeze, chronic cough, and annual loss of forced expiratory volume in 1 second $\left(\mathrm{FEV}_{1}\right) .{ }^{16,17}$ Furthermore, AHR has been shown to be an important risk factor in patients with established asthma and COPD: more severe AHR is associated with more severe symptoms and a more rapid decline in $\mathrm{FEV}_{1} \cdot{ }^{14,15}$

\section{The Overlap Between Asthma and COPD}

Asthma is traditionally described as an allergic disease that develops during childhood and is characterized by reversible AO. In contrast, COPD is typically related to smoking tobacco, develops later in life, and is characterized by incompletely reversible airflow limitation. Although both diseases share $\mathrm{AO}$ as a common feature, they are at opposite ends of the spectrum of obstructive airway disease that is seen in clinical practice. There is, however, a considerable pathologic and functional overlap between asthma and COPD, particularly among the elderly, who may have components of both diseases (overlap syndrome).

Airway inflammation is the central component of all different phenotypes of obstructive airway diseases (asthma, COPD, emphysema, and chronic bronchitis) that can exist in various combinations (Figure 2). Epidemiologic studies report an increased frequency of overlapping diagnoses with advancing age, with an estimated prevalence of $<10 \%$ in patients younger than 50 years and $>50 \%$ in patients aged 80 years or older. ${ }^{18}$ Patient groups that have features of asthmaCOPD overlap syndrome include smokers with asthma and nonsmokers with long-standing asthma who progress to COPD.

Given that overlapping features become more prevalent with increasing age and a history of smoking, the prevailing clinical impression is that with age there is often a progression from the reversible airflow obstruction of the young asthmatic patient to the more irreversible obstruction of the older patient with COPD. ${ }^{19}$ While COPD tends to be inevitably progressive, many patients with long-standing asthma experience a slowly progressive decrease of lung function, as measured by $\mathrm{FEV}_{1}$, secondary to airway remodeling. ${ }^{1,20}$ Increasing age, smoking, AHR, and dis-
Figure 2. The classic Venn diagram used to describe the overlap of the pathologic and clinical features of chronic bronchitis, emphysema, and asthma. The subsets comprising chronic obstructive pulmonary disease (COPD) are shaded. Chronic bronchitis, emphysema, and airway obstruction are independent effects of cigarette smoking and may occur in various combinations. Patients with chronic bronchitis, emphysema, or both are not considered to have COPD unless they have airflow obstruction. Patients with asthma whose airflow obstruction is completely reversible do not have COPD, whereas those who develop a partially reversible airflow obstruction over time are considered to have asthma-COPD overlap syndrome ("asthma with a COPD component" or "COPD with asthmatic features"). Modified with permission from the American Thoracic Society. ${ }^{21}$

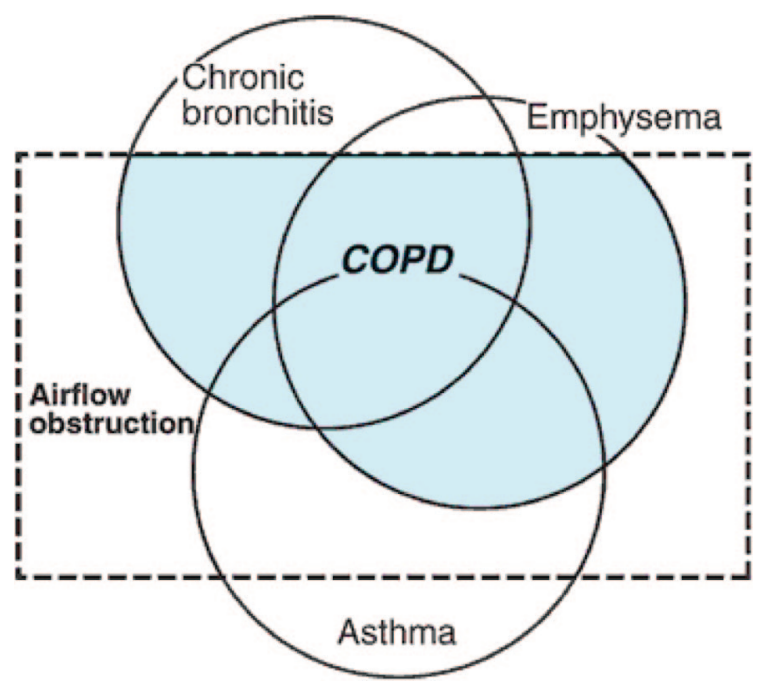

ease exacerbations in both asthma and COPD are risk factors for airway remodeling and accelerated loss of lung function. ${ }^{17,22}$

Finally, the overlap syndrome of asthma and COPD is supported by the "Dutch hypothesis," which states that asthma and AHR predispose patients to COPD later in life and that asthma, COPD, chronic bronchitis, and emphysema are different expressions (or components) of a single airway disease. The presence of these components is influenced by host and environmental factors. ${ }^{23}$

\section{Therapeutic Responses in Asthma, COPD, and Overlap Syndrome}

A comprehensive review of the available treatments for obstructive airway diseases is beyond the scope 
of this article; however, it is important to appreciate that the nature of the underlying inflammation differs between asthma and COPD, as does the response to different classes of medications. Although specific interventions vary by disease, the treatment goals of asthma and COPD are similar and driven primarily by patient-centered outcomes such as controlling symptoms, optimizing health status and quality of life, and preventing exacerbations (ie, reducing their frequency and severity).

In general, therapies for COPD have a much more limited effect compared with those for asthma. While inhaled corticosteroids (ICSs) are the cornerstone of the pharmacologic management of patients with persistent asthma, inhaled bronchodilators ( $\beta 2$-agonists and anticholinergics) are the therapeutic mainstay for patients with COPD. There are no disease-modifying medications currently available that can alter the progression of $\mathrm{AO}$ in either asthma or COPD. Smoking cessation, however, is an essential component of the successful management of any obstructive airway disease.

At present there is no randomized clinical trial data to help guide therapeutic interventions in asthma-COPD overlap syndrome. In fact, patients with overlapping asthma and COPD are frequently excluded from treatment trials for either condition, which limits the generalizability of these trials in this neglected patient population. However, practical treatment principles are similar to those for asthma or COPD and involve a comprehensive therapy directed toward airway inflammation, $\mathrm{AO}$, and AHR.

\section{Glucocorticoid Treatment in Asthma and COPD}

Glucocorticoids are the most potent anti-inflammatory medications available for the treatment of asthma and COPD. When indicated, ICSs remain the mainstay of glucocorticoid therapy for stable disease because of their proven effectiveness and, in recommended doses, few systemic adverse effects. Their slow onset of action compared with systemic steroids, however, makes the latter the preferred treatment for acute exacerbations.

\section{Systemic Glucocorticoids in the Treatment of Acute Exacerbations of Asthma and COPD}

The primary therapeutic goals for acute asthma or COPD exacerbations are the rapid reversal of airflow obstruction and the correction, if necessary, of severe hypercapnia or hypoxemia. Hence early and aggressive treatment of acute exacerbations is critical. The major pharmacologic classes available to manage acute exacerbations include inhaled shortacting bronchodilators, systemic glucocorticoids, and, in the case of COPD, antibiotics. ${ }^{1,2}$

When added to the bronchodilator therapies described below, systemic glucocorticoids improve symptoms and lung function and decrease the length of hospital stay. ${ }^{24,25}$ Patients with continued dyspnea and wheezing despite intensive bronchodilator therapy most likely have persistent airflow obstruction secondary to airway edema, inflammation, and intraluminal mucus plugging. The latter pathologic changes usually respond to glucocorticoid therapy and typically resolve at a pace far slower than smooth muscle constriction.

Although respiratory infections are the most common triggers of asthma and COPD exacerbations, antibiotic treatment is currently indicated only for patients with moderate to severe COPD exacerbations. Current clinical practice guidelines do not recommended antibiotics for asthma exacerbations because most respiratory infections that trigger asthma attacks are viral rather than bacterial. ${ }^{26-28}$ Recent evidence, however, suggests a greater role for antibiotics than is indicated in the current guidelines. Certain antibiotics, macrolides in particular, have both antimicrobial and antiinflammatory actions that may be useful in the treatment of some patients with asthma or COPD. ${ }^{29-31}$ Further studies are needed to clarify the potential role of macrolides in specific subgroups of patients with either stable disease or acute exacerbations.

\section{ICSs in the Treatment of Stable Asthma and COPD}

There is now ample evidence that ICSs are effective against the eosinophilic inflammation in asthma but much less effective against the primarily neutrophilic inflammation seen in COPD. ${ }^{32}$ Furthermore, neutrophilic (noneosinophilic) asthma is associated with increased steroid resistance, whereas concomitant eosinophilic inflammation in COPD is associated with a greater response to corticosteroids. While the use of ICSs is recommended as the first-line therapy for all stages of persistent asthma, ICS treatment in COPD is recommended for symptomatic patients with $\mathrm{FEV}_{1}<50 \%$ predicted and/or frequent exacerbations despite an optimal regiment with a long-acting inhaled bronchodilator. ${ }^{2,33}$ However, ICS therapy may be warranted earlier (ie, at the same time that the long-acting 
inhaled bronchodilator is initiated) if there are signs of an asthmatic component to the COPD. ${ }^{34}$ Long-term monotherapy with ICS is not recommended in COPD because inhaled bronchodilators have greater benefits with fewer adverse effects.

\section{Bronchodilator Treatment in Asthma and COPD}

There are 2 major classes of inhaled bronchodilators: $\beta 2$-agonists and anticholinergic agents; within each of these classes, both short-acting and longacting formulations are available. The presence of acute reversibility with the use of bronchodilators does not completely distinguish asthma from COPD. Patients with either condition can benefit from bronchodilators and should be given a trial to assess their response. Furthermore, bronchodilators have been consistently shown to induce longterm improvements in symptoms, exercise capacity, and airflow obstruction in patients with COPD, even when there is no spirometric improvement after a single test dose. ${ }^{35,36}$

The bronchodilator responses in asthma and COPD differ both quantitatively and in their spirometric patterns. While asthmatic patients typically show an increase in $\mathrm{FEV}_{1}$ alone or in both $\mathrm{FEV}_{1}$ and forced vital capacity (FVC), patients with COPD typically display an isolated increase in FVC or in both $\mathrm{FEV}_{1}$ and FVC (ie, less hyperinflation). ${ }^{37,38}$

\section{Bronchodilators in the Treatment of Acute Exacerbations of Asthma and COPD}

Short-acting bronchodilators should be used aggressively during an acute exacerbation, and nebulized formulations are recommended for those who are very ill and unable to generate the flow required for effective use of other modalities. Inhaled shortacting $\beta 2$-agonists (eg, albuterol) are the mainstay of therapy for an acute exacerbation of asthma or COPD because of their rapid onset of action. The more gradual bronchodilation of short-acting anticholinergics (eg, ipratropium) compared with $\beta 2$ agents makes them inappropriate monotherapy for acute exacerbations. However, the addition of ipratropium to albuterol therapy leads to more rapid and complete improvement in bronchoconstriction and decreases hospitalization rates in patients with COPD exacerbations or moderate to severe asthma attacks. $^{39,40}$

\section{Bronchodilators in the Treatment of Stable Asthma and COPD}

All symptomatic patients with asthma or COPD should be prescribed an inhaled short-acting bronchodilator to be used on an as-needed basis for the relief of acute symptoms. The regular use of shortacting bronchodilators as a maintenance treatment for asthma or COPD has been replaced by the more effective and convenient long-acting bronchodilators. Long-acting bronchodilators are effective when used as monotherapy in patients with COPD, but they should always be combined with an anti-inflammatory medication (eg, an ICS or a leukotriene-modifying agent) when treating persistent asthma of any severity. ${ }^{1,15}$

While inhaled $\beta 2$-agonists are considered to be first-line bronchodilators in the treatment of asthma, inhaled anticholinergics, when given at effective doses, can cause significant bronchodilation that is comparable to that found after treatment with $\beta 2$-agonists. ${ }^{41-44}$ There is increasing evidence that long-acting anticholinergics could be as effective as long-acting $\beta 2$-agonists in controlling asthma symptoms. ${ }^{42-44}$ The use of anticholinergics adds little to $\beta 2$-agonist treatment in chronic stable asthma, although patients who have more severe AO seem to benefit the most from this combination therapy. Therefore, a trial of combination therapy in individual patients not controlled by one bronchodilator may still be justified. ${ }^{1,45}$ Inhaled anticholinergics are suggested as an alternative bronchodilator for patients who do not tolerate $\beta 2$-agonists, and they are considered the drug of choice for treating asthma induced by $\beta$-blockers.

On the other hand, in patients with COPD anticholinergics provide equivalent or perhaps improved bronchodilation compared with $\beta 2$-agonists. ${ }^{46-48}$ There is insufficient evidence to recommend one bronchodilator over another when treating COPD symptoms. Combination therapy $(\beta 2$-agonists and anticholinergics) produces a greater bronchodilator response than either one alone in patients with stable COPD. ${ }^{49}$ The choice between $\beta 2$-agonists, anticholinergics, and combination therapy depends on the availability of the medications and on each patient's individual response in terms of both symptom relief and side effects. ${ }^{2}$ The progressive nature of the disease, the more severe $\mathrm{AO}$, and the more limited effect of bronchodilators compared with asthma explain why 
Table 1. Characteristic Similarities and Differences Between Asthma, Chronic Obstructive Pulmonary Disease (COPD), and the Overlap Syndrome

\begin{tabular}{|c|c|c|c|}
\hline & Asthma & COPD & Overlap Syndrome \\
\hline Pathology & $\begin{array}{l}\text { Chronic airway inflammation, } \\
\text { typically eosinophilic and } \\
\text { driven by CD4 cells. } \\
\text { Neutrophilic inflammation } \\
\text { has been observed in the } \\
\text { airways of some asthmatics } \\
\text { and is associated with } \\
\text { increased steroid resistance. }\end{array}$ & $\begin{array}{l}\text { Chronic airway inflammation, } \\
\text { typically neutrophilic and } \\
\text { driven by CD8 cells. } \\
\text { Eosinophilic inflammation } \\
\text { has been observed in the } \\
\text { airways of some patients with } \\
\text { COPD and is associated with } \\
\text { greater steroid sensitivity. }\end{array}$ & $\begin{array}{l}\text { Pathologic overlap in the } \\
\text { inflammatory profiles } \\
\text { of both asthma and } \\
\text { COPD, particularly } \\
\text { among the elderly. }\end{array}$ \\
\hline Pathophysiology & $\begin{array}{l}\text { Reversible airway obstruction; } \\
\text { progressive deterioration over } \\
\text { time is uncommon. }\end{array}$ & $\begin{array}{l}\text { Partially reversible airway } \\
\text { obstruction; progressive } \\
\text { deterioration overtime is } \\
\text { typical. }\end{array}$ & $\begin{array}{l}\text { Functional overlap } \\
\text { between asthma and } \\
\text { COPD, particularly } \\
\text { among the elderly. }\end{array}$ \\
\hline \multicolumn{4}{|c|}{ Treatment of acute exacerbations } \\
\hline $\begin{array}{l}\text { Systemic corticosteroids \& } \\
\text { inhaled bronchodilators }\end{array}$ & $\begin{array}{l}\text { Improve symptoms and lung } \\
\text { function and decrease the } \\
\text { length of hospital stay. }\end{array}$ & $\begin{array}{l}\text { Improve symptoms and lung } \\
\text { function and decrease the } \\
\text { length of hospital stay. }\end{array}$ & No data available. \\
\hline \multicolumn{4}{|c|}{ Maintenance treatment of stable disease } \\
\hline ICSs & $\begin{array}{l}\text { The mainstay of treatment in } \\
\text { patients with persistent } \\
\text { asthma. }\end{array}$ & $\begin{array}{l}\text { Less effective response. ICSs } \\
\text { are recommended for } \\
\text { patients with more severe } \\
\text { COPD (FEV }{ }_{1}<50 \% \text { of } \\
\text { predicted) whose symptoms } \\
\text { are not optimally controlled } \\
\text { with inhaled bronchodilators. } \\
\text { ICS monotherapy is not } \\
\text { recommended. }\end{array}$ & No data available. \\
\hline Inhaled bronchodilators & $\begin{array}{l}\text { Inhaled short-acting } \beta 2 \text {-agonists } \\
\text { are the mainstay of treatment } \\
\text { for intermittent asthma. } \\
\text { Inhaled long-acting } \beta 2 \text {-agonists } \\
\text { monotherapy is not } \\
\text { recommended. }\end{array}$ & $\begin{array}{l}\text { The mainstay of treatment in } \\
\text { patients with COPD; inhaled } \\
\text { anticholinergics may be more } \\
\text { effective than inhaled } \beta 2- \\
\text { agonists as monotherapy in } \\
\text { COPD. }\end{array}$ & No data available. \\
\hline
\end{tabular}

$\mathrm{FEV}_{1}$, forced expiratory volume in 1 second; ICS, inhaled corticosteroid.

most patients COPD require combination bronchodilator therapy at some point during the course of their disease. ${ }^{50}$

\section{Summary}

Asthma and COPD are common obstructive airway diseases that represent a challenge to physicians in their diagnosis and management, with significant overlap in their clinical features, physiologic parameters, and airway inflammation (asthma-COPD overlap syndrome). Airway remodeling, a well-established feature in both diseases, may account for at least some of these reported similarities. The prevalence of overlap syndrome increases with age, making the distinction between asthma and COPD difficult and often imprecise in the elderly population. Table 1 summarizes some of the characteristic features of these 2 diseases.

\section{References}

1. Expert Panel Report 3: Guidelines for the Diagnosis and Management of Asthma. National Heart, Lung, and Blood Institute, National Asthma Education and Prevention Program. Bethesda, MD: U.S. Department of Health and Human Services, National Institutes of Health, National Heart, Lung, and Blood Institute; 2007.

2. Global Initiative for Chronic Obstructive Lung Disease. Global strategy for the diagnosis, management and prevention of chronic obstructive pulmonary disease NHLBI/WHO Workshop Report. Updated 2011. Available from: http://www.goldcopd.org. Accessed February 15, 2013.

3. Douwes J, Gibson P, Pekkanen J, Pearce N. Noneosinophilic asthma: importance and possible mechanisms. Thorax 2002;57:643-8.

4. Cowan DC, Cowan JO, Palmay R, Williamson A, Taylor DR. Effects of steroid therapy on inflammatory cell subtypes in asthma. Thorax 2010;65:384-90.

5. Chalmers GW, Macleod KJ, Little SA, Thomson LJ, McSharry CP, Thomson NC. Influence of cigarette 
smoking on inhaled corticosteroid treatment in mild asthma. Thorax 2002;57:226-30.

6. Chaudhuri R, Livingston E, McMahon AD, Thomson L, Borland W, Thomson NC. Cigarette smoking impairs the therapeutic response to oral corticosteroids in chronic asthma. Am J Respir Crit Care Med 2003;168:1308-11.

7. Chanez P, Vignola AM, O'Shaugnessy T, et al. Corticosteroid reversibility in COPD is related to features of asthma. Am J Respir Crit Care Med 1997; 155:1529-34.

8. O'Byrne PM, Pedersen S, Lamm CJ, Busse WW; START Investigators Group. Severe exacerbations and decline in lung function in asthma. Am J Respir Crit Care Med 2009;179:19-24.

9. Sapey E, Stockley RA. COPD exacerbations. 2: aetiology. Thorax 2006;61:250-8.

10. Hamid Q, Tulic MK. New insights into the pathophysiology of the small airways in asthma. Ann Thorac Med 2007;2:28-33.

11. Hogg JC, Chu F, Utokaparch S, et al. The nature of small-airway obstruction in chronic obstructive pulmonary disease. N Engl J Med 2004;350:2645-53.

12. Sköld CM. Remodeling in asthma and COPD-differences and similarities. Clin Respir J. 2010;4(Suppl 1): $20-7$.

13. Vestbo J, Hansen EF. Airway hyperresponsiveness and COPD mortality. Thorax 2001;56(Suppl 2): ii11-4.

14. Postma DS, Kerstjens HAM. Characteristics of airway hyperresponsiveness in asthma and chronic obstructive pulmonary disease. Am J Respir Crit Care Med 1998;158:S187-92.

15. Scichilone N, Battaglia S, La Sala A, Bellia V. Clinical implications of airway hyper-responsiveness in COPD. Int J Chron Obstruct Pulmon Dis 2006;1: 49-60.

16. Brutsche MH, Downs SH, Schindler C, et al. Bronchial hyperresponsiveness and the development of asthma and COPD in asymptomatic individuals: SAPALDIA Cohort Study. Thorax 2006;61:671-7.

17. Gibson PG, Simpson JL. The overlap syndrome of asthma and COPD: what are its features and how important is it? BMJ 2009;64:728-35.

18. Soriano JB, Davis KJ, Coleman B, Visick G, Mannino D, Pride NB. The proportional Venn diagram of obstructive lung disease: two approximations from the United States and the United Kingdom. Chest 2003;124:474-81.

19. Fabbri LM, Romagnoli M, Corbetta L, et al. Differences in airway inflammation in patients with fixed airflow obstruction due to asthma or chronic obstructive pulmonary disease. Am J Respir Crit Care Med 2003;167:418-24.

20. Panettieri RA J., Covar R, Grant E, Hillyer EV, Bacharier L. Natural history of asthma: persistence versus progression-does the beginning predict the end? J Allergy Clin Immunol 2008;121:607-13.
21. American Thoracic Society. Standards for the diagnosis and care of patients with chronic obstructive pulmonary disease. Am J Respir Crit Care Med 1995;152:S77-121.

22. Rasmussen F, Taylor DR, Flannery EM, et al. Risk factors for airway remodeling in asthma manifested by a low postbronchodilator FEV1/vital capacity ratio: a longitudinal population study from childhood to adulthood. Am J Respir Crit Care Med 2002;165: 1480-8.

23. Orie NGM. The Dutch hypothesis. Chest 2000;117: 299.

24. Fanta CH, Rossing TH, McFadden ER Jr. Glucocorticoids in acute asthma. A critical controlled trial. Am J Med 1983;74:845-51.

25. Niewoehner DE, Erbland ML, Deupree RH, et al. Effect of systemic glucocorticoids on exacerbations of chronic obstructive pulmonary disease. Department of Veterans Affairs Cooperative Study Group. N Engl J Med 1999;340:1941-7.

26. Bach PB, Brown C, Gelfand SE, et al. Management of acute exacerbations of chronic obstructive pulmonary disease: a summary and appraisal of published evidence. Ann Intern Med 2001;134:600-20.

27. Ram FS, Rodriguez-Roisin R, Granados-Navarrete A, Garcia-Aymerich J, Barnes NC. Antibiotics for exacerbations of chronic obstructive pulmonary disease. Cochrane Database Syst Rev 2006;(2):CD004403.

28. Rothberg MB, Pekow PS, Lahti M, Brody O, Skiest DJ, Lindenauer PK. Antibiotic therapy and treatment failure in patients hospitalized for acute exacerbations of chronic obstructive pulmonary disease. JAMA 2010;303:2035-42.

29. Koutsoubari I, Papaevangelou V, Konstantinou GN, et al. Effect of clarithromycin on acute asthma exacerbations in children: an open randomized study. Pediatr Allergy Immunol 2012;23:385-90.

30. Hahn DL, Grasmick M, Hetzel S, Yale S. Azithromycin for bronchial asthma in adults: an effectiveness trial. J Am Board Fam Med 2012;25:442-59.

31. Albert RK, Connett J, Bailey WC, et al. Zithromycin for prevention of exacerbations of COPD. N Engl J Med 2011;365:689-98.

32. Keatings VM, Jatakanon A, Worsdell YM, Barnes PJ. Effects of inhaled and oral glucocorticoids on inflammatory indices in asthma and COPD. Am J Respir Crit Care Med 1997;155:542-8.

33. Calverley PM, Anderson JA, Celli B, et al. Salmeterol and fluticasone propionate and survival in chronic obstructive pulmonary disease. N Engl J Med 2007;356:775-89.

34. Leigh R, Pizzichini MM, Morris MM, Maltais F, Hargreave FE, Pizzichini E. Stable COPD: predicting benefit from high-dose inhaled corticosteroid treatment. Eur Respir J 2006;27:964-71.

35. Sin DD, McAlister FA, Man SF, Anthonisen NR. Contemporary management of chronic obstructive 
pulmonary disease: scientific review. JAMA 2003; 290:2301-12.

36. Man SF, McAlister FA, Anthonisen NR, Sin DD. Contemporary management of chronic obstructive pulmonary disease: clinical applications. JAMA 2003; 290:2313-6.

37. Chhabra SK, Bhatnagar S. Comparison of bronchodilator responsiveness in asthma and chronic obstructive pulmonary disease. Indian J Chest Dis $\mathrm{Al}-$ lied Sci 2002;44:91-7.

38. Donohue JF. Therapeutic responses in asthma and COPD-bronchodilators. Chest 2004;126(2 Suppl): 125S-37S; discussion 159S-61S.

39. Shrestha M, O'Brien T, Haddox R, et al. Decreased duration of emergency department treatment of chronic obstructive pulmonary disease exacerbations with the addition of ipratropium bromide to $\beta$-agonist therapy. Ann Emerg Med 1991;20:1206-9.

40. Rodrigo GJ, Castro-Rodriguez JA. Anticholinergics in the treatment of children and adults with acute asthma: a systematic review with meta-analysis. Tho$\operatorname{rax} 2005 ; 60: 740-6$.

41. Chhabra SK, Pandey KK. Comparison of acute bronchodilator effects of inhaled ipratropium bromide and salbutamol in bronchial asthma. J Asthma 2002;39:375-81.

42. Peters SP, Kunselman SJ, Icitovic N, et al. Tiotropium bromide step-up therapy for adults with uncontrolled asthma: a randomized trial. $\mathrm{N}$ Engl J Med 2010;363:1715-26.

43. Kerstjens HA, Disse B, Schröder-Babo W, et al. Tiotropium improves lung function in patients with severe uncontrolled asthma: a randomized controlled trial. J Allergy Clin Immunol 2011;128:308-14.

44. Bateman ED, Kornmann O, Schmidt P, Pivovarova A, Engel M, Fabbri LM. Tiotropium is noninferior to salmeterol in maintaining improved lung function in B16-Arg/Arg patients with asthma. J Allergy Clin Immunol 2011;128:315-22.

45. Westby M, Benson M, Gibson P. Anticholinergic agents for chronic asthma in adults. Cochrane Database Syst Rev 2004;(3):CD003269.

46. Braun SR, Levy SF. Comparison of ipratropium bromide and albuterol in chronic obstructive pulmonary disease: a three-center study. Am J Med 1991;91: 28S-32S.

47. Niewoehner DE, Rice K, Cote C, et al. Prevention of exacerbations of chronic obstructive pulmonary disease with tiotropium, a once-daily inhaled anticholinergic bronchodilator: a randomized trial. Ann Intern Med 2005;143:317-26.

48. Donohue JF, van Noord JA, Bateman ED, et al. A 6-month, placebo-controlled study comparing lung function and health status changes in COPD patients treated with tiotropium or salmeterol. Chest 2002; 122:47-55.

49. In chronic obstructive pulmonary disease, a combination of ipratropium and albuterol is more effective than either agent alone. An 85-day multicenter trial. COMBIVENT Inhalation Aerosol Study Group. Chest 1994;105:1411-9.

50. Nichols J. Combination inhaled bronchodilator therapy in the management of chronic obstructive pulmonary disease. Pharmacotherapy 2007;27:447-54. 